\title{
Genome-Wide Sequencing Reveals Two Major Sub-Lineages in the Genetically Monomorphic Pathogen Xanthomonas Campestris Pathovar Musacearum
}

\author{
Arthur Wasukira ${ }^{1,2}$, Johnbosco Tayebwa ${ }^{1,2}$, Richard Thwaites ${ }^{3}$, Konrad Paszkiewicz ${ }^{1}$, \\ Valente Aritua $^{2,3, \dagger}$, Jerome Kubiriba ${ }^{2}$, Julian Smith ${ }^{3}$, Murray Grant ${ }^{1}$ and \\ David J. Studholme ${ }^{1, *}$
}

1 Biosciences, University of Exeter, Geoffrey Pope Building, Stocker Road, Exeter EX4 4QD, UK; E-Mails: awasukira@gmail.com (A.W.); tayebwajb@gmail.com (J.T.); k.h.paszkiewicz@exeter.ac.uk (K.P.);m.r.grant@exeter.ac.uk (M.G.)

2 National Crops Resources Research Institute (NaCRRI), Kampala 7084, Uganda; E-Mails: arituavalentine@yahoo.com (V.A.); jkubiriba@kari.go.ug (J.K.)

3 The Food and Environment Research Agency, Sand Hutton, York YO41 1LZ, UK; E-Mails: richard.thwaites@fera.gsi.gov.uk (R.T.); julian.smith@fera.gsi.gov.uk (J.S.)

$\dagger$ Present address: International Centre for Tropical Agriculture (CIAT), Kawanda Agricultural Research Institute, Kampala 6247, Uganda.

* Author to whom correspondence should be addressed; E-Mail: d.j.studholme@exeter.ac.uk.

Received: 10 June 2012; in revised form: 24 June 2012 / Accepted: 26 June 2012 /

Published: 4 July 2012

\begin{abstract}
The bacterium Xanthomonas campestris pathovar musacearum $(\mathrm{Xcm})$ is the causal agent of banana Xanthomonas wilt (BXW). This disease has devastated economies based on banana and plantain crops (Musa species) in East Africa. Here we use genome-wide sequencing to discover a set of single-nucleotide polymorphisms (SNPs) among East African isolates of $X \mathrm{~cm}$. These SNPs have potential as molecular markers for phylogeographic studies of the epidemiology and spread of the pathogen. Our analysis reveals two major sub-lineages of the pathogen, suggesting that the current outbreaks of BXW on Musa species in the region may have more than one introductory event, perhaps from Ethiopia. Also, based on comparisons of genome-wide sequence data from multiple isolates of $X \mathrm{~cm}$ and multiple strains of $X$. vasicola pathovar vasculorum, we identify genes specific to $X \mathrm{~cm}$ that could be used to specifically detect Xcm by PCR-based methods.
\end{abstract}


Keywords: banana Xanthomonas wilt; whole-genome sequencing; SNP; molecular markers; Ensete ventricosum; Xanthomonas vasicola

\section{Introduction}

The bacterium Xanthomonas campestris pathovar musacearum $(X \mathrm{~cm})$ is the causal agent of banana Xanthomonas wilt (BXW). This disease has devastated economies based on banana and plantain crops (Musa species) in East Africa [1]. Xcm was first described as a wilt-causing pathogen on enset (Ensente ventricosum), a plant closely related to banana that is a staple crop in the highlands of Ethiopia [2]. In 1974 Yirgou and Bradbury [3] wrote that "Great care should be taken to see that enset wilt does not escape and establish itself on banana in other parts of the world where it could pose a serious problem on this crop". Ominously, one and a half decades later, a major epidemic of this disease was reported in Uganda [4]. Subsequently it has spread into many banana-growing regions around the Great Lakes in Uganda, Kenya, Tanzania, Democratic Republic of Congo, Rwanda and Burundi [4-7]. Efforts are underway to tackle this pathogen by a number of different measures including cultural practices [8] and genetic modification of the crop $[9,10]$.

Although currently classified as a member of the species Xanthomonas campestris, we recently showed that $X \mathrm{~cm}$ is more likely to be a strain of the species Xanthomonas vasicola [11]. We previously [12] generated complete genome sequences for a single isolate of $X \mathrm{~cm}$ from banana in Uganda (NCPPB4381) and for a single isolate of $X$. vasicola pathovar vasculorum (Xvv) that is non-pathogenic on banana and was isolated from sugarcane in Zimbabwe (NCPPB702). These two isolates share identical gyrase B DNA sequences, consistent with their very close evolutionary relationship [11,13].

Differences between these two genome sequences revealed several candidate genes that might play a role in adaptation to the banana host. These may also be useful tools in identifying genes for deployment of disease resistance. Specifically, these included homologues of effectors secreted and translocated by the type III secretion system (T3SS). T3SS effectors have previously been shown to contribute to host-specificity acting as virulence and/or avirulence factors [14]. In common with most previously sequenced Xanthomonas genomes, Xcm encodes homologues of the effectors AvrBs2, AvrGf1, XopF, XopK, XopL, XopN, XopP, XopQ, XopR, XopX and XopZ as well as homologues of XopA, XopB, XopG, XopH, XopI, XopY, XopAA, XopAD, XopAE and XopAK, which are found in some other Xanthomonas species [12,14]. Xcm also encodes homologues of $P$. syringae effectors HopW1 and HopAF1 and Ralstonia solanacearum putative effector RipT [12]. Xcm encodes two predicted YopJ-like C55 cysteine proteases (RefSeq accessions ZP_06491730 and ZP_06492219) that are absent from Xvv 702. On the other hand, $X v v 702$ encodes a close homologue (ZP_06483517) of XopAF (also known as AvrXv3), which is absent from $X c m$ [12].

Previous work showed that $X \mathrm{~cm}$ is a highly monomorphic pathogen and no specific genetic differences have yet been detected among different isolates using traditional typing and diagnostic methods $[13,15]$. Affordable complete genome sequencing now makes it feasible to identify cryptic genetic diversity among isolates of a genetically monomorphic pathogen [16], though this approach is only just starting to be applied to monomorphic phytopathogens [17]. 
Here we use genome-wide sequencing to discover a set of single-nucleotide polymorphisms (SNPs) among East African isolates of $\mathrm{Xcm}$. These SNPs have potential as molecular markers for phylogeographic studies of the epidemiology and spread of the pathogen. Our analysis reveals the presence of at least two major sub-lineages of the pathogen; Xcm isolates from Uganda, Kenya, Tanzania and Burundi are genetically distinct from isolates collected in Ethiopia, DR Congo and Rwanda, suggesting that the current outbreaks of BXW on Musa species in the region may have more than one introduction.

\section{Results and Discussion}

\subsection{Genome Sequencing}

We used the Illumina GA2x sequencing platform to generate genome-wide sequence data for 13 isolates of $X \mathrm{~cm}$ available from the National Collection of Plant Pathogenic Bacteria (NCPPB). We also sequenced a further three African isolates of $X v v$, a pathovar that is very closely related to $X c m$ but non-pathogenic on banana. We also included in our analyses the genome sequence data from $\mathrm{Xcm}$ NCPPB4381 and $X v v$ NCPPB702 that we published previously [12]. Table 1 lists the sequenced isolates and the depth to which each was sequenced. We submitted all raw sequence data to the Sequence Read Archive [18]. Note that another isolate from Tanzania, NCPPB4393, is described in the NCPPB's catalogue as Xcm, but we previously sequenced its genome and showed that it is actually Xanthomonas sacchari [19]. We generated genome assemblies de novo for NCPPB2005, NCPPB4379, NCPPB4380, NCPPB4384, NCPPB4392, NCPPB4394, NCPPB1326, NCPPB1381 and NCPPB206 using Velvet 1.1.04 [20]. These have been submitted to GenBank [21] with accession numbers AKBE00000000, AKBF00000000, AKBG00000000, AKBH00000000, AKBI00000000,

Table 1. Isolates of $X$. campestris pv. musacearum $(X \mathrm{~cm})$ and $X$. vasicola pv. vasculorum $(X v v)$ subjected to genome-wide sequencing. All $X \mathrm{~cm}$ isolates were originally collected from diseased banana plants except for NCPPB2005, which was isolated from Ensete ventricosum. All Xvv isolates were originally collected from sugarcane, except for NCPPB206, which was isolated from maize.

\begin{tabular}{llcl}
\hline \multicolumn{1}{c}{ Isolate } & \multicolumn{1}{c}{ Source and Date of Isolation } & Coverage & SRA Accession \\
\hline$X c m$ NCPPB2005 & Ethiopia 1967 & $72 \times$ & SRR489154.7 \\
\hline$X c m$ NCPPB2251 & Ethiopia 1969 & $13 \times$ & SRR494492.2 \\
\hline$X c m$ NCPPB4379 & Uganda (Kayunga) 2007 & $102 \times$ & SRR494484.2 \\
\hline$X c m$ NCPPB4380 & Uganda (Kiboga) 2007 & $113 \times$ & SRR494485.2 \\
\hline$X c m$ NCPPB4381 & Uganda (Luwero) 2007 & $56 \times$ & SRR020203.3 \\
\hline$X c m$ NCPPB4383 & Uganda (Wakiso) 2007 & $11 \times$ & SRR494493.2 \\
\hline$X c m$ NCPPB4384 & Uganda (Nakaongola) 2007 & $13 \times$ & SRR494488.2 \\
\hline$X c m$ NCPPB4387 & D. R. Congo (Kivu province) 2007 & $16 \times$ & SRR494495.2 \\
\hline$X c m$ NCPPB4389 & Rwanda (Gisenyi province) 2007 & $72 \times$ & SRR494498.3 \\
\hline$X c m$ NCPPB4392 & Tanzania (Muleba district, Kagera region) 2007 & $92 \times$ & SRR494489.1 \\
\hline$X c m$ NCPPB4394 & Tanzania (Muleba district, Kagera region) 2007 & $117 \times$ & SRR494490.2 \\
\hline$X c m$ NCPPB4395 & Tanzania (Muleba district, Kagera region) 2007 & $13 \times$ & SRR494496.1 \\
\hline$X c m$ NCPPB4433 & Burundi 2008 &
\end{tabular}


Table 1. Cont.

\begin{tabular}{llcl}
\hline \multicolumn{1}{c}{ Isolate } & \multicolumn{1}{c}{ Source and Date of Isolation } & Coverage & SRA Accession \\
\hline$X c m$ NCPPB4434 & Kenya (Teso district) 2008 & $15 \times$ & SRR494497.1 \\
\hline$X v v$ NCPPB206 & South Africa 1948 & $70 \times$ & SRR494500.3 \\
\hline$X v v$ NCPPB702 & Zimbabwe 1959 & $35 \times$ & SRR020202.3 \\
\hline$X v v$ NCPPB1326 & Zimbabwe 1962 & $63 \times$ & SRR494491.5 \\
\hline$X v v$ NCPPB1381 & Zimbabwe 1962 & $66 \times$ & SRR494499.3 \\
\hline
\end{tabular}

AKBJ00000000, AKBK00000000, AKBL00000000 and AKBM00000000. The most contiguous of these assemblies was for NCPPB4384. This consisted of 84 scaffolds, of which the 12 longest scaffolds were each at least $154 \mathrm{~Kb}$ long and accounted for more than $2.5 \mathrm{Mb}$; that is the $\mathrm{N}_{50}$ length was $154 \mathrm{~Kb}$ for NCPPB4384. The $\mathrm{N}_{50}$ lengths for the other $\mathrm{Xcm}$ assemblies were $56 \mathrm{~Kb}$ (NCPPB2005), $146 \mathrm{~Kb}$ (NCPPB4379), $147 \mathrm{~Kb}$ (NCPPB4380), $87 \mathrm{~Kb}$ (NCPPB4392) and $151 \mathrm{~Kb}$ (NCPPB4394).

\subsection{Distinguishing $\mathrm{Xcm}$ from $\mathrm{Xvv}$}

The currently used method for identifying BXW is by isolation of bacteria from the infected plant and performing fatty acid and metabolic analyses [4]. However, this approach is only appropriate once symptoms become visible, by which time it may be too late to control or eradicate the pathogen. An alternative approach, amenable to the rapid detection and identification of bacterial plant pathogens is the use of the polymerase chain reaction (PCR). A specific assay for detecting $X \mathrm{~cm}$ has recently been proposed based on PCR amplification of the $h r p B$ gene [22]. However, this gene is also conserved in $X v v$ and this assay was unable to distinguish between $X c m$ and non-banana-pathogenic isolates $X v v$ NCPPB702 and NCPPB1326 [22]. Another study [23] generated several PCR primer pairs that were highly specific for $X c m$ but this study did not utilize $X c m$ or $X v v$ genomic sequence but rather used sequences from a range of other xanthomonads and so the candidate primers had to be tested for specificity by trial and error. Another recent study [24] exploited our previous [12] Xcm and Xvv draft genome sequence data to rationally design primers specific for $X \mathrm{~cm}$. However, this was based on genome sequence from a single isolate of $X v v$ and a single isolate of $X \mathrm{~cm}$. Until now, little was known about sequence diversity among isolates. Therefore, we identified a set of genes that are conserved in all of the sequenced isolates of $X \mathrm{~cm}$ but are absent from all the sequenced isolates of $X v v$ and are therefore candidates for use in an Xcm-specific PCR assay. Examples of these genes are listed in Table 2. Note that this list of genes was not generated by aligning assembled genome sequences. We aligned raw unassembled sequence reads against the previously published Xcm NCPPB4381 reference genome sequence [12] using the Burrows-Wheeler Aligner BWA [25]. This approach has the advantage of avoiding assembly artifacts and problems arising from incomplete assemblies. In our BWA alignments of raw Illumina sequence reads versus the reference genome sequence, the full length of each gene was covered by reads (depth of one or greater) from all our Xcm Illumina sequence datasets. Each of these genes has no matches (i.e., zero depth of) to any sequence reads in our $X v v$ Illumina datatsets (as judged from the BWA alignments). 
Table 2. Candidate genes for development of an Xcm-specific PCR-based assay. The listed genes conserved in all of the sequenced $\mathrm{Xcm}$ isolates but absent from all of the sequenced $X v v$ isolates. Presence or absence of each gene was assessed based on alignment of Illumina sequence reads from each isolate against the $X \mathrm{~cm}$ NCPPB4381 reference genome sequence (RefSeq: ACHT00000000) using BWA [25].

\begin{tabular}{ll}
\hline RefSeq Locus tag & Predicted Gene Product \\
\hline XcampmN_010100002667 & hypothetical protein \\
\hline XcampmN_010100009057 & general secretion pathway protein D \\
\hline XcampmN_010100016989 & transposase \\
\hline XcampmN_010100016984 & phage-related integrase \\
\hline XcampmN_010100014552 & hypothetical protein \\
\hline XcampmN_010100013878 & DNA-cytosine methyltransferase \\
\hline XcampmN_010100013483 & hypothetical protein \\
\hline XcampmN_010100011643 & conjugal transfer relaxosome component TraJ \\
\hline XcampmN_010100011578 & hypothetical protein \\
\hline XcampmN_010100011573 & Fis family transcriptional regulator \\
\hline XcampmN_010100011558 & hypothetical protein \\
\hline XcampmN_010100011553 & hypothetical protein \\
\hline XcampmN_010100010854 & hypothetical protein \\
\hline XcampmN_010100010849 & XRE family transcriptional regulator \\
\hline XcampmN_010100006985 & hypothetical protein \\
\hline XcampmN_010100004971 & exported protein \\
\hline XcampmN_010100004961 & virulence regulator \\
\hline XcampmN_010100004956 & hypothetical protein \\
\hline XcampmN_010100004736 & hypothetical protein \\
\hline XcampmN_010100001342 & ISXo2 putative transposase \\
\hline XcampmN_010100001332 & ABC-type antimicrobial peptide transport system ATPase component \\
\hline XcampmN_010100001327 & RND family efflux transporter MFP subunit \\
\hline XcampmN_010100013888 & ISxac1 transposase \\
\hline XcampmN_010100011563 & putative DNA methylase \\
\hline XcampmN_010100004966 & integrase \\
\hline XcampmN_010100001337 & peptide ABC transporter permease \\
\hline XcampmN_010100013883 & restriction endonuclease-like protein \\
\hline XcampmN_010100000225 & putative secreted protein \\
\hline XcampmN_010100000622 & fimbrillin \\
\hline XcampmN_010100015677 & methyltransferase \\
\hline XcampmN_010100016677 & Putative acetylhydrolase \\
\hline
\end{tabular}

\subsection{The Sequenced Xcm Isolates Comprise a Single Monophyletic Clade}

We identified SNPs among the $X c m$ and $X v v$ isolates based on BWA [25] alignments of our Illumina sequence data against the $X$. oryzae pv. oryzae MAFF 311018 reference genome sequence (RefSeq: NC_007705). Based on nucleotides found at 21,525 polymorphic positions we generated the maximum likelihood phylogenetic tree shown in Figure 1. This clearly groups all of the sequenced 
$\mathrm{Xcm}$ isolates into a single distinct clade that is closely related to but distinct from the sequenced $X v v$ isolates.

Figure 1. East African isolates of Xanthomonas campestris pv. musacearum (Xcm) from banana and enset comprise a monophletic clade closely related to Xanthomonas vasicola. A maximum likelihood phylogenetic tree was generated as described in the Experimental Section. The tree was rooted with X. oryzae pv. oryzae MAFF 311018 ("Xoo") as the outgroup. The tree is based on 21,525 SNPs in 19 taxa. Branch lengths are drawn to scale and measured in the number of substitutions per site. Bootstrap values are given as percentages from 500 bootstrap trials.

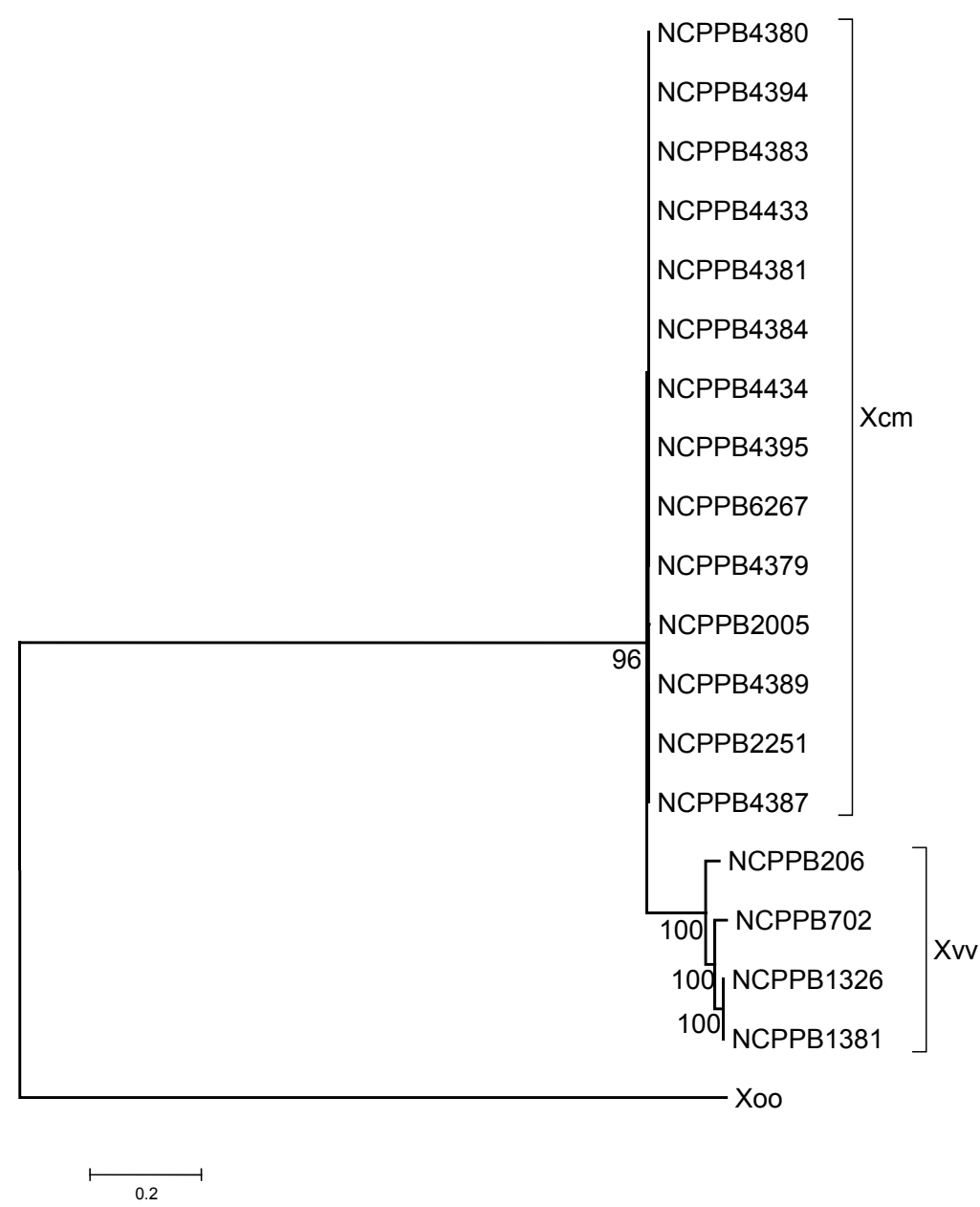

2.4. Xcm Isolates from Uganda, Kenya, Tanzania and Burundi are Genetically Distinct from Isolates from Ethiopia, DR Congo and Rwanda

We next identified SNPs among the $X c m$ and $X v v$ isolates based on BWA [25] alignments of our Illumina sequence data against the $\mathrm{Xcm}$ NCPPB4381 reference genome sequence (RefSeq: ACHT00000000). Out of 2,908,042 nt over which there was no ambiguity, 2,907,999 were invariant across all isolates; that is the $\mathrm{Xcm}$ genomes shared at least $99.9985 \%$ identity. Based on nucleotides found at 243 polymorphic positions we generated the maximum likelihood phylogenetic tree shown in Figure 2. This clearly delineates the $\mathrm{Xcm}$ clade into two distinct sub-lineages, I and II. Sub-lineage I include isolates from Ethiopia, DR Congo and Rwanda whilst Sub-lineage II includes 
isolates from Uganda, Tanzania, Burundi and Kenya. The two sub-lineages are distinguishable from each other by 86 polymorphic positions. These are listed in full in the Supplementary Material and in part in Table 3.

Figure 2. Isolates of $X \mathrm{~cm}$ from Burundi, Kenya, Tanzania and Uganda comprise a separate sub-lineage that is distinct from isolates from and D. R. Congo, Ethiopia and Rwanda. A maximum likelihood phylogenetic tree was generated as described in the Experimental Section. The position of the root was inferred from the phylogeny presented in Figure 1. The tree is based on 272 SNPs in 14 taxa. Branch lengths are drawn to scale and measured in the number of substitutions per site. Bootstrap values are given as percentages from 500 bootstrap trials.

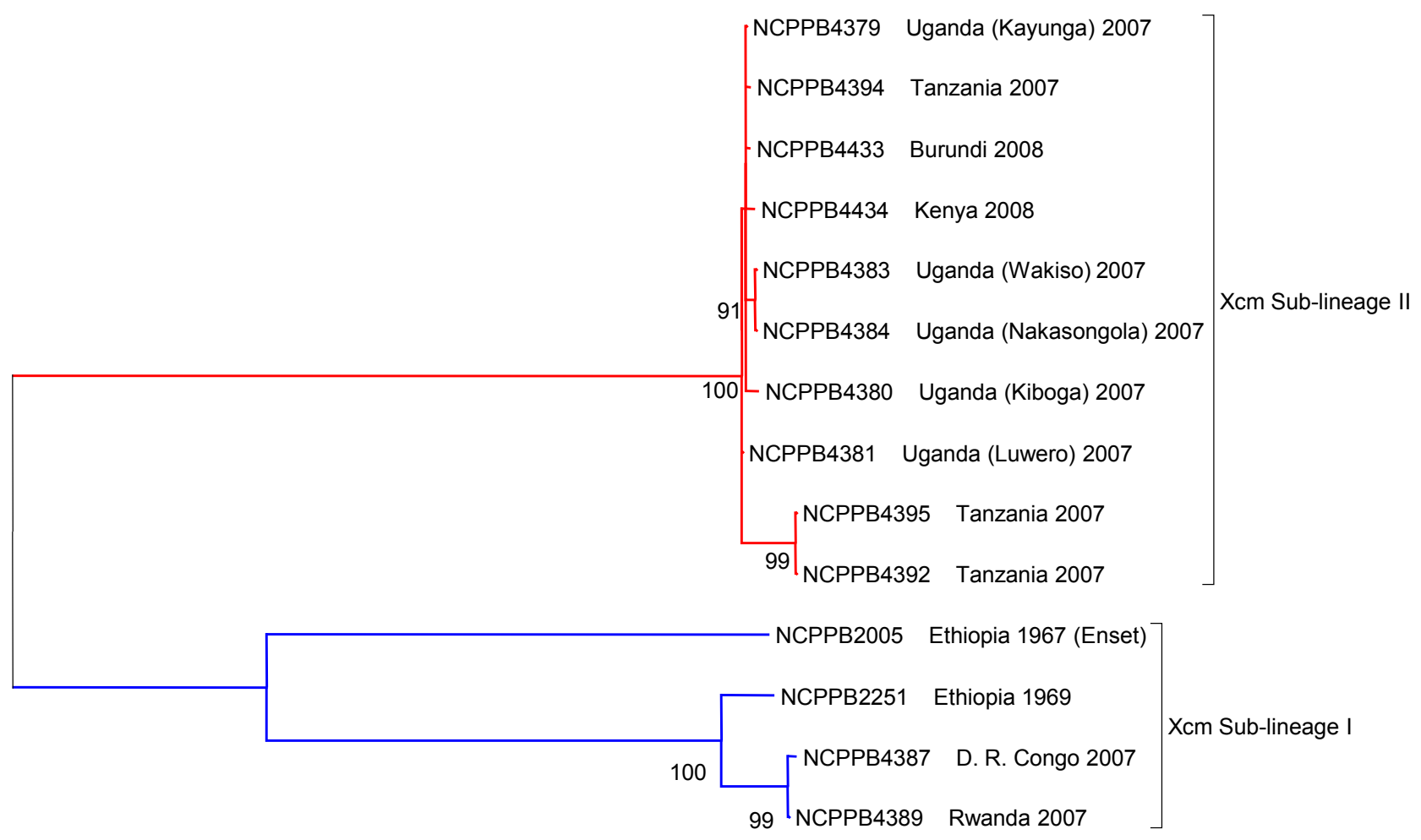

Table 3. Examples of non-silent single-nucleotide polymorphisms that distinguish $\mathrm{Xcm}$ sub-lineages I (Ethiopia, DR Congo and Rwanda) and II (Uganda, Kenya, Tanzania, Burundi).

\begin{tabular}{ccccl}
\hline RefSeq Accession & Position & I & II & Locus Tag and Predicted Gene Product \\
\hline NZ_ACHT01000013 & 861 & g & c & XcampmN_010100000120 putative ISXo8 transposase \\
\hline NZ_ACHT01000014 & 6000 & a & g & $\begin{array}{l}\text { XcampmN_010100000165 putative monovalent cation/H+ antiporter } \\
\text { subunit A }\end{array}$ \\
\hline NZ_ACHT01000034 & 8898 & t & c & XcampmN_010100000807 putative integrase protein \\
\hline NZ_ACHT01000045 & 1261 & a & g & $\begin{array}{l}\text { XcampmN_010100001162 bifunctional aspartate kinase/diaminopimelate } \\
\text { decarboxylase protein }\end{array}$ \\
\hline NZ_ACHT01000045 & 45,548 & a & c & XcampmN_010100001377 chemotaxis protein \\
\hline NZ_ACHT01000059 & 1907 & c & t & XcampmN_010100001687 putative sugar transporter component \\
\hline
\end{tabular}


Table 3. Cont.

\begin{tabular}{lcccl}
\hline RefSeq Accession & Position & I & II & Locus Tag and Predicted Gene Product \\
\hline NZ_ACHT01000101 & 995 & g & t & XcampmN_010100003517 soluble lytic murein transglycosylase \\
\hline NZ_ACHT01000104 & 13,081 & t & g & XcampmN_010100003612 GTP-dependent nucleic acid-binding protein \\
& & & & EngD \\
\hline NZ_ACHT01000113 & 10,410 & t & g & XcampmN_010100004062 acetyltransferase (GNAT) family protein \\
\hline NZ_ACHT01000236 & 10,652 & t & c & XcampmN_010100007340 metallopeptidase \\
\hline NZ_ACHT01000242 & 10,465 & a & c & XcampmN_010100007585 dihydrolipoamide acetyltransferase \\
\hline NZ_ACHT01000294 & 2184 & g & t & XcampmN_010100009424 xanthan biosynthesis glucuronosyltransferase \\
& & & & GumK \\
\hline NZ_ACHT01000345 & 1576 & t & c & XcampmN_010100010814 cytochrome C peroxidase \\
\hline NZ_ACHT01000402 & 4858 & t & c & XcampmN_010100012145 heavy metal transporter \\
\hline NZ_ACHT01000404 & 632 & g & a & XcampmN_010100012200 tryptophan halogenase \\
\hline NZ_ACHT01000500 & 23,584 & a & g & XcampmN_010100016057 putative polysaccharide deacetylase \\
\hline NZ_ACHT01000520 & 5360 & a & g & XcampmN_010100016692 5-methyltetrahydrofolate-homocysteine \\
& & & & methyl transferase \\
\hline NZ_ACHT01000549 & 7371 & a & c & XcampmN_010100018271 two-component system sensor protein \\
\hline NZ_ACHT01000560 & 4001 & t & c & XcampmN_010100018673 exodeoxyribonuclease III \\
\hline NZ_ACHT01000590 & 927 & c & t & XcampmN_010100019303 RNA polymerase sigma factor \\
\hline NZ_ACHT01000626 & 10,220 & t & c & XcampmN_010100019733 putative glutathionylspermidine synthase \\
\hline NZ_ACHT01000634 & 2345 & t & c & XcampmN_010100019848 beta-mannosidase precursor \\
\hline NZ_ACHT01000644 & 2590 & g & a & XcampmN_010100020168 two-component system sensor protein \\
\hline NZ_ACHT01000694 & 10,665 & a & t & XcampmN_010100022153 peptide-acetyl-coenzyme A transporter family \\
& & & & protein \\
\hline NZ_ACHT01000720 & 19,485 & t & c & XcampmN_010100023003 drug:proton antiporter (19121-20371) \\
\hline
\end{tabular}

The geographic locations of the sequenced $\mathrm{Xcm}$ isolates are shown in Figure 3. It has been widely assumed that the outbreaks in Uganda, and subsequent outbreaks in neighboring countries, ultimately originated in Ethiopia, with the pathogen perhaps being inadvertently transmitted via international trade. Consistent with this model, the $\mathrm{Xcm}$ isolates from DR Congo and Rwanda do indeed show extremely high levels of genetic similarity to Ethiopian isolate NCPPB2251. However, the isolates from Uganda, Kenya, Tanzania and Burundi show a distinct genotype, characterized by the 86 consistent SNP differences. This is not consistent with a single introduction from Ethiopia into East Africa.

Our data do not exclude the possibility that the current outbreaks can ultimately be traced back to Ethiopia; it is possible that both lineages I and II are endemic there and it is simply by chance that the two available isolates happen to belong to the DR Congo/Rwanda sub-lineage I. There is an urgent need to collect a range of isolates from Ethiopia and survey their genotypes to ascertain the level of genetic diversity in this pathogen's presumed centre of origin. Genotyping new isolates should be possible and will be expedited by developing these newly discovered SNPs into PCR based molecular markers. Similarly, there is a pressing need to survey genotypes of a much larger collection of isolates from outbreaks in all the banana growing areas to uncover the routes of geographical spread at a much higher degree of resolution. Ideally a survey of genotypes should be conducted on isolates for which precise details are available on the date and the geographic location at which they are collected. 
Figure 3. Geographical distribution of the two major sub-lineages of $X \mathrm{~cm}$. The approximate geographical locations are indicated for each of the fully sequenced $\mathrm{Xcm}$ isolates from Ethiopia (NCPPB2005 and NCPPB2251), Uganda (NCPPB4379, NCPPB4380, NCPPB4381, NCPPB4383 and NCPPB4384), Kenya (NCPPB4434), Tanzania (NCPPB4392, NCPPB4394 and NCPPB4395), DR Congo (NCPPB4387), Rwanda (NCPPB4389) and Burundi (NCPPB4433). Blue rectangles indicate locations of isolates belonging to sub-lineage I and red ovals indicate those of sub-lineage II.

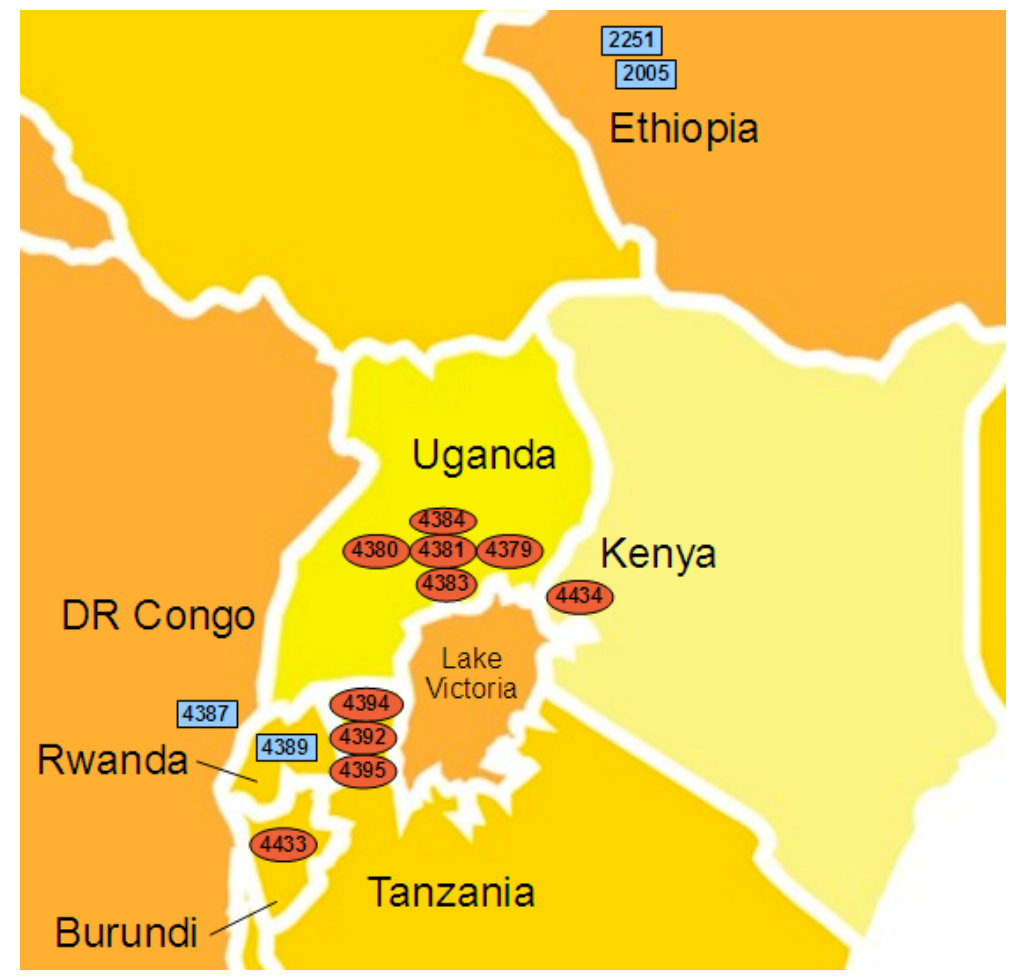

It should also be noted that although we have categorized the isolates according to the country in which they were collected, paths of transmission may be more influenced by geographical boundaries rather than by political ones. For example, although Rwanda shares two of its borders with Uganda and Tanzania it is somewhat isolated from them by lake and forest.

All of the available isolates from Uganda were collected in 2007 from sites in the central region geographically close to Mukono where the disease was first reported and probably all represent the same single outbreak. It would be interesting to compare these with isolates from outbreaks in Kabale (near Rwanda) or Kasese (near DR Congo).

All of the available isolates from Tanzania also belonged to sub-lineage II along with those from Uganda. The disease was reported in Tanzania shortly after it was discovered in Uganda and there has been unconfirmed speculation that it may have been inadvertently carried to Tanzania by banana alcohol traders from the Buganda region, close to where the sequenced Ugandan isolates were collected. Our molecular sequence data are consistent with this but do not provide definitive proof.

Although BXW was reported in DR Congo after it was reported in Uganda, the field pictures first sent to Uganda from DR Congo, showed greater devastation. It is not clear where banana Xanthomonas wilt occurred first: DR Congo or Uganda. There is a lot of movement of people and bananas from Congo to Rwanda and back, conflicts notwithstanding, and so it is perhaps not surprising that we 
observe isolates from these two countries belonging to the same sub-lineage I. However, the close relationship between an Ethiopian isolate and those in Rwanda and DRC is not so easily explained unless it is by sampling bias or by one-off international travel; if disease spread was primarily determined by movement of local people and bananas between countries, then we would instead expect isolates from Rwanda, Uganda and DR Congo to cluster together.

\subsection{Comparison of Xcm Isolated from Enset Versus Xcm Isolated from Banana}

Most of the available isolates of $X \mathrm{~cm}$ were originally isolated from banana. The exception is NCPPB2005, which was isolated from Ensete ventricosum in Ethiopia in 1967. This isolate clearly falls within $\mathrm{Xcm}$ sub-lineage I (Figure 2). This enset-associated isolate differs from the banana-associated isolates NCPPB2251, NCPPB4387 and NCPPB4389 at 67 SNP positions listed in the Supplementary Material. Some examples of these differences are listed in Table 4 and include non-silent polymorphisms in several potential virulence genes (e.g., homologues of $h r p F$ and a gene encoding a HopW1 T3SS effector). However, since $X \mathrm{~cm}$ is able to infect both banana and enset [2,3] it is not clear whether these differences have any biological significance. It would be interesting to survey a much larger sample of isolates from both banana and enset to search for any significant associations between genotype and host species that might reveal adaptation.

Table 4. Examples of non-silent single-nucleotide polymorphisms that distinguish NCPPB2251 from banana versus NCPPB2005 from enset.

\begin{tabular}{|c|c|c|c|c|c|}
\hline Refseq Accession & Position & $\begin{array}{c}\text { NCPPB } 2005 \\
\text { (enset) }\end{array}$ & $\begin{array}{c}\text { NCPPB } 2251 \\
\text { (Banana) }\end{array}$ & $\begin{array}{c}\text { NCPPB } 4389 \\
\text { (Banana) }\end{array}$ & Locus Tag and Predicted Gene Product \\
\hline NZ_ACHT01000041 & 15,615 & $\mathrm{c}$ & $\mathrm{t}$ & $\mathrm{t}$ & XcampmN_010100000977 hemolysin III \\
\hline NZ_ACHT01000072 & 4507 & $\mathrm{a}$ & $\mathrm{c}$ & $\mathrm{c}$ & XcampmN_010100002109 VirB3 protein \\
\hline NZ_ACHT01000140 & 1116 & $\mathrm{c}$ & $\mathrm{t}$ & $\mathrm{t}$ & $\begin{array}{l}\text { XcampmN_010100004536 LacI family } \\
\text { transcription regulator }\end{array}$ \\
\hline NZ_ACHT01000199 & 8012 & $\mathrm{~g}$ & $\mathrm{t}$ & g & $\begin{array}{l}\text { XcampmN_010100006143 type III } \\
\text { secreted effector HopW1 }\end{array}$ \\
\hline NZ_ACHT01000215 & 3229 & $\mathrm{c}$ & $\mathrm{t}$ & $\mathrm{c}$ & XcampmN_010100006660 HrpF protein \\
\hline NZ_ACHT01000236 & 9512 & $\mathrm{c}$ & $\mathrm{t}$ & $\mathrm{t}$ & $\begin{array}{l}\text { XcampmN_010100007340 } \\
\text { metallopeptidase }\end{array}$ \\
\hline NZ_ACHT01000294 & 31,553 & $\mathrm{~g}$ & a & a & $\begin{array}{l}\text { XcampmN_010100009559 MFS } \\
\text { transporter }\end{array}$ \\
\hline NZ_ACHT01000303 & 7530 & $\mathrm{a}$ & $\mathrm{c}$ & $\mathrm{c}$ & $\begin{array}{l}\text { XcampmN_010100009850 histidine } \\
\text { kinase/response regulator hybrid protein }\end{array}$ \\
\hline NZ_ACHT01000332 & 2191 & $\mathrm{a}$ & $\mathrm{g}$ & g & $\begin{array}{l}\text { XcampmN_010100010574 putative } \\
\text { filamentous hemagglutinin-like protein }\end{array}$ \\
\hline NZ_ACHT01000360 & 1961 & a & $\mathrm{g}$ & $\mathrm{g}$ & $\begin{array}{l}\text { XcampmN_010100011266 two- } \\
\text { component system sensor protein }\end{array}$ \\
\hline NZ_ACHT01000374 & 12,027 & $\mathrm{t}$ & $\mathrm{c}$ & $\mathrm{c}$ & $\begin{array}{l}\text { XcampmN_010100011573 Fis family } \\
\text { transcriptional regulator }\end{array}$ \\
\hline NZ_ACHT01000388 & 5277 & $\mathrm{t}$ & g & g & $\begin{array}{l}\text { XcampmN_010100011860 AraC family } \\
\text { transcriptional regulator }\end{array}$ \\
\hline NZ_ACHT01000396 & 3578 & $\mathrm{c}$ & g & $\mathrm{g}$ & XcampmN_010100011920 catalase \\
\hline NZ_ACHT01000439 & 5166 & $\mathrm{c}$ & $\mathrm{g}$ & $\mathrm{g}$ & $\begin{array}{l}\text { XcampmN_010100013743 ECF subfamily } \\
\text { RNA polymerase sigma factor }\end{array}$ \\
\hline
\end{tabular}


Table 4. Cont.

\begin{tabular}{lccccc}
\hline Refseq Accession & Position & $\begin{array}{c}\text { NCPPB 2005 } \\
\text { (enset) }\end{array}$ & $\begin{array}{c}\text { NCPPB 2251 } \\
\text { (Banana) }\end{array}$ & $\begin{array}{c}\text { NCPPB 4389 } \\
\text { (Banana) }\end{array}$ & Locus Tag and Predicted Gene Product \\
\hline NZ_ACHT01000532 & 743 & $\mathrm{c}$ & $\mathrm{t}$ & $\mathrm{t}$ & XcampmN_010100017284 beta-glucosidase \\
\hline NZ_ACHT01000560 & 2783 & $\mathrm{c}$ & $\mathrm{t}$ & $\mathrm{t}$ & $\begin{array}{l}\text { XcampmN_010100018663 molybdopterin } \\
\text { biosynthesis }\end{array}$ \\
\hline NZ_ACHT01000668 & 1036 & $\mathrm{c}$ & $\mathrm{a}$ & $\mathrm{a}$ & $\begin{array}{l}\text { XcampmN_010100021383 ABC transporter } \\
\text { permease }\end{array}$ \\
\hline NZ_ACHT01000690 & 6284 & $\mathrm{t}$ & $\mathrm{g}$ & $\mathrm{g}$ & $\begin{array}{l}\text { XcampmN_010100022008 isocitrate } \\
\text { dehydrogenase }\end{array}$ \\
\hline
\end{tabular}

\subsection{Loss of Phage-Associated Genes in Some Xcm Isolates}

In addition to surveying SNPs, we also searched for loss or gain of genes. By aligning sequence reads against the previously published NCPPB4381 genome assembly and systematically comparing gene-coverage in each of the alignments, we were able to identify a genomic region (GenBank: GG699410.1) that showed differential coverage among different isolates of $\mathrm{Xcm}$ (Figure 4). This region shows significant similarity at the amino acid and nucleotide sequence levels to two previously sequenced phage: Xanthomonas phage Cfc1 (RefSeq: NC_001396.1) [26] and Stenotrophomonas phage phiSHP2 (GenBank: HM150760.1). Specifically, two Tanzanian isolates (NCPPB4392 and NCPPB4395) appear to have completely lost at least 17 genes from this region, while Ethiopian isolate NCPPB2005 has lost 11 of the same genes. Interestingly, another isolate from the same area of Tanzania (NCPPB4394) appears to have these genes intact as do all the Ugandan, Kenyan, Rwandan and Burundi isolates. Furthermore, there is a high concentration of SNPs in this genomic region. Therefore, it seems likely that this genomic region represents the relic of a phage or similar mobile element that is in the process of degenerating, convergently, in some members of both sub-lineages.

\subsection{Experimental Validation of Genetic Polymorphisms}

One of the major motivations for comparing these genome sequences is to provide a resource for generating molecular markers that can be used epidemiological and biogeographical studies on a much larger panel of isolates without the need for whole-genome sequencing using, for example, the polymerase chain reaction (PCR). Therefore, we used the results of our genome comparisons to design pairs of PCR primers that can be used to distinguish between the two sub-lineages of $X c m$ (Table 5). A similar approach could also be taken to assay other classes of SNPs identified from the genome sequence data.

To experimentally validate SNPs, we used an approach based on digestion of PCR products with restriction enzymes. Many of the SNPs that we identified are predicted to fall within restriction sites. For example, position 6150 in RefSeq accession NZ_ACHT0100081 is a G that falls within an AluI restriction site $(A \mathbf{G} \downarrow C T)$. However, in NCPPB2005 and the other members of sub-lineage $I$, this $G$ is substituted for an A abolishing the recognition sequence for the AluI restriction enzyme (see Supplementary Files for a figure illustrating this SNP and several others). There are no other AluI sites in the vicinity of this SNP. We generated a pair of primers flanking approximately $250 \mathrm{bp}$ either side of the SNP and amplified this 500 bp sequence by PCR. The two alleles could then be readily 
distinguished by digestion with AluI (see Figure 5). We used the same approach to design assays for three other SNPs (see Table 5 and Figure 5).

Figure 4. Loss of phage-related genes in two Tanzanian isolates and one Ethiopian isolate of $X \mathrm{~cm}$. The figure shows alignments of genomic sequence reads from six $\mathrm{Xcm}$ isolates versus two contigs from the previously published NCPPB4381 genome assembly [12] as viewed in IGV. (Panel A): contig_scf_7264_3425_27 (GenBank: ACHT01000345.1); (Panel B): contig_scf_7264_3425_29 (GenBank: ACHT01000346.1). Both contigs are contained within genomic scaffold scf_7264_3425 (GenBank: GG699410.1). The vertical axes are the depth of coverage by aligned sequence reads. Coloured vertical bars indicate discrepancies with the NCPPB4381 reference sequence, including SNPs. The horizontal axis is the position on the contig. Positions of predicted genes are indicated below the horizontal axis. Hypothetical genes of unknown function are indicated by white arrows while homologues of characterized genes are indicated by coloured arrows.

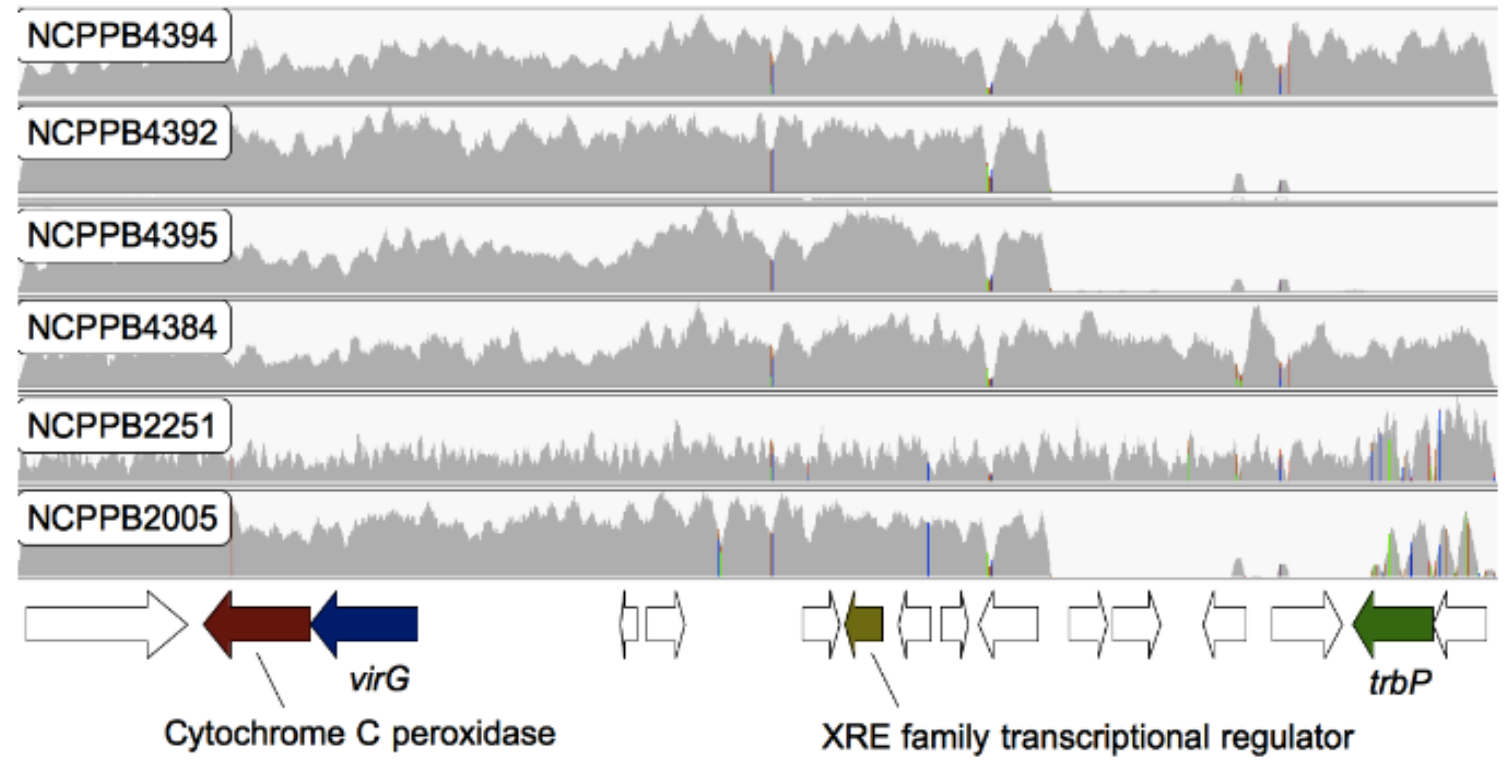

(A)

\begin{tabular}{|l|l|l|}
\hline NCPPB4394 & \\
\hline NCPPB4392 \\
\hline NCPPB4395 \\
\hline NCPPB4384 \\
\hline NCPPB2251 \\
\hline NCPPB2005
\end{tabular}

(B) 
Figure 5. Experimental validation of single-nucleotide polymorphisms (SNPs) between the two sub-lineages of Xanthomonas campestris pathovar musacearum $(\mathrm{Xcm})$. We amplified specific sequence fragments of approximately $500 \mathrm{bp}$ flanking single-nucleotide polymorphisms that we had identified from whole-genome sequencing. Polymerase chain reaction (PCR) was performed on genomic DNA from four isolates from sub-lineage I (NCPPB2005, NCPPB2251, NCPPB4387 and NCPPB4389) and from four isolates of sublineage II (NCPPB4383, NCPPB4433, NCPPB4434 and NCPPB4392). The sequences of the PCR primers are given in Table 5. We digested each of the PCR products with a restriction enzyme (AluI, EcoRI, FokI, NdeI or RsaI). We ran the digested PCR products on a $2 \%$ agarose gel alongside a 100 bp ladder (Promega G210A) in which the brightest band, marked with a black arrow, indicates $500 \mathrm{bp}$.

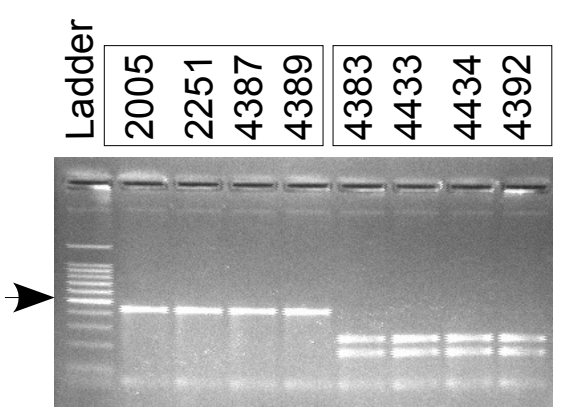

NZ_ACHT01000081 Alul

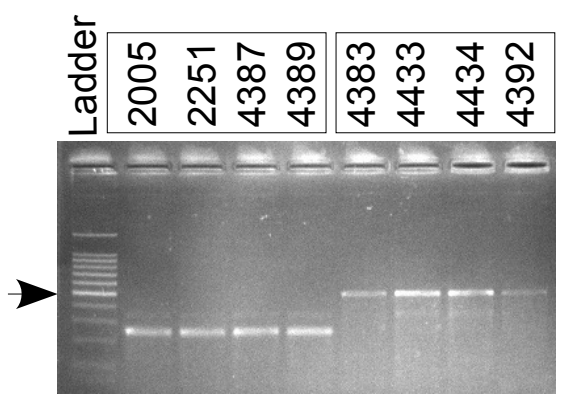

NZ_ACHT01000124 Alul

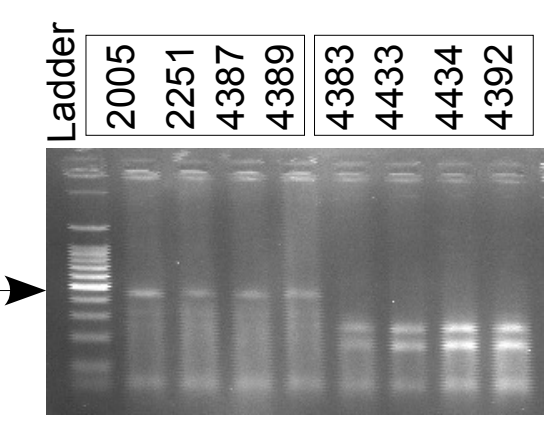

NZ_ACHT01000112 Fokl

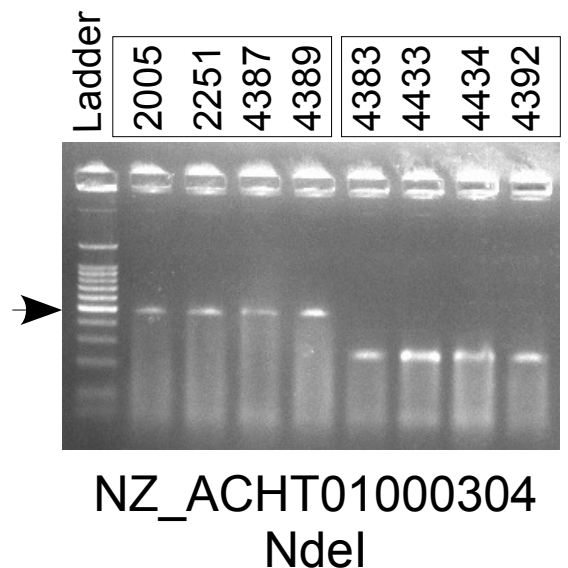

Table 5. Polymerase chain reaction (PCR) primers used for distinguishing the two sub-lineages by restriction fragment length polymorphisms.

\begin{tabular}{lcc}
\hline Primer Sequences & $\begin{array}{c}\text { Target Sequence RefSeq Accession } \\
\text { Number and Coordinates }\end{array}$ & Restriction Enzyme \\
\hline $\begin{array}{l}\text { GAGCTCCTGCGCCGATGC } \\
\text { GTGAGCGTAAAGGCGGCTATTCTA }\end{array}$ & NZ_ACHT01000081: 5900-6398 & AluI \\
\hline $\begin{array}{l}\text { CGGCGTGGTTTGCCTTTGC } \\
\text { CGTACGGCCTGGCGGTGAT }\end{array}$ & NZ_ACHT01000112: 10863-11347 & FokI \\
\hline $\begin{array}{l}\text { TCACCTGTTCGATGCGGCC } \\
\text { GCTACTGGCTGTCGCGGC }\end{array}$ & NZ_ACHT01000124: 5385-5873 & AluI \\
\hline ATGTTTGCCGATACCTGGATGC & NZ_ACHT01000304: $10080-10567$ & NdeI \\
\hline GCATGCTTGCCGGTTTCGACGA & & \\
\hline
\end{tabular}




\section{Experimental Section}

Bacterial strains were obtained from the National Collection of Plant Pathogenic Bacteria (NCPPB) at FERA. DNA library preparation and genome sequencing using the Illumina GA2x were performed using standard Illumina protocols as previously described [12].

For DNA preparation, bacterial strains were grown overnight at $28{ }^{\circ} \mathrm{C}$ in $10 \mathrm{~mL}$ King Broth shaken at $200 \mathrm{rpm}$. Cells were harvested by centrifugation and re-suspended in TE buffer $(50 \mathrm{mM}$ Tris-HCl, 40 mM EDTA, pH 8.0). Bacterial cells cultured overnight in Kings Broth were pelleted, lysed with $12 \mu \mathrm{L}$ of $20 \mathrm{mg} / \mathrm{mL}$ lysozyme and RNase at $10 \mathrm{mg} / \mathrm{mL}$ and incubated at $25{ }^{\circ} \mathrm{C}$ for $10 \mathrm{~min}$. Further lysis was done with $17 \mu \mathrm{L} 10 \%$ sodium dodecyl sulfate and incubated on ice for $5 \mathrm{~min}$. Proteins were dissolved with $170 \mu \mathrm{L}$ of $8 \mathrm{M}$ ammonium acetate, vortexed vigorously for $30 \mathrm{~s}$ centrifuged at $4{ }^{\circ} \mathrm{C}$ at maximum speed for 15 min. DNA was precipitated with isopropanol and re-dissolved in $100 \mu \mathrm{L}$ of $10 \mathrm{mM}$ Tris, $\mathrm{pH} 8.0$, and $1 \mathrm{mM}$ Na2EDTA.

DNA amplification was performed in $30 \mu \mathrm{L}$ reaction volumes containing $3 \mu \mathrm{L}$ 10X PCR buffer, $1.2 \mu \mathrm{L}$ of $50 \mathrm{mM} \mathrm{MgCl} 2,2.4 \mu \mathrm{L}$ of $2.5 \mathrm{mM}$ dNTP, $1.5 \mu \mathrm{L}$ of $10 \mu \mathrm{M}$ each primer, 2 ng DNA and $1 \mathrm{U}$ recombinant Taq DNA polymerase. Amplification was performed using a thermocycler with initial denaturation $\left(95^{\circ} \mathrm{C}, 5 \mathrm{~min}\right)$, followed by 35 cycles of denaturation $\left(95^{\circ} \mathrm{C}, 0.5 \mathrm{~min}\right)$, annealing $\left(60^{\circ} \mathrm{C}\right.$, $0.5 \mathrm{~min})$ and extension $\left(72{ }^{\circ} \mathrm{C}, 0.5 \mathrm{~min}\right)$, with a final extension $\left(72{ }^{\circ} \mathrm{C}, 10 \mathrm{~min}\right)$. The amplified products were electrophoretically separated in $4 \%(\mathrm{w} / \mathrm{v})$ agarose gel at $80 \mathrm{~V}$ for $1 \mathrm{~h}$ in TAE buffer and visualized with UV light after staining in ethidium bromide $(0.5 \mu \mathrm{g} \mathrm{mL})$.

Amplified DNA fragments were digested with restriction endonucleases (AluI, Fok or NdeI). The restriction analysis was performed with $2.5 \mathrm{U}$ of the endonuclease using the buffer and temperature recommended by the manufacturers (New England Biolabs). Restriction fragments were separated in a $8 \%(\mathrm{w} / \mathrm{v})$ agarose gel with $100 \mathrm{bp}$ ladder (Promega, G210A) at $100 \mathrm{~V}$ for $1 \mathrm{~h}$ in TAE buffer and visualized with UV light after staining in ethidium bromide $(0.5 \mu \mathrm{g} \mathrm{mL})$.

We used BWA [25] to align Illumina sequence reads against a reference genome sequence and used IGV [27] to visualize the alignments (see Figure 4). We used MEGA5 for phylogenetic analyses. De novo assembly of Illumina sequence reads was performed using Velvet 1.1.04 [20]. We discarded any sequence reads that contained one or more ' $N$ ' prior to assembly.

We used a very conservative approach to infer SNPs from alignments of Illumina reads against the previously published $\mathrm{Xcm}$ NCPPB4381 reference draft genome assembly. To avoid false positives and false negatives, we only used those regions of the $X \mathrm{~cm}$ genome with a coverage depth of five or more for every sequenced $\mathrm{Xcm}$ genome and where there was at least $95 \%$ consensus among the sequence reads within each isolate. Just over $60 \%$ of the length $(2,908,042$ out of $4,782,144 \mathrm{nt})$ of the $\mathrm{Xcm}$ NCPPB4381 genome fulfilled these two criteria. In other words, for $60 \%$ of the $X \mathrm{~cm}$ genome, there was sufficient quantity and consistency in our data to be almost certain of the sequence in all of the fourteen isolates; for the remaining $40 \%$ of the genome, there was some degree of ambiguity in the data for at least one of the isolates.

Phylogenetic relationships were inferred using a maximum likelihood method based on the TamuraNei model [28] conducted using the MEGA5 [29] software package. Bootstrap consensus trees inferred from 500 replicates were taken to represent the evolutionary history of the taxa analyzed. Branches corresponding to partitions reproduced in fewer than $50 \%$ bootstrap replicates were 
collapsed. Initial tree(s) for the heuristic search were obtained automatically as follows. When the number of common sites was $<100$ or fewer than one quarter of the total number of sites, the maximum parsimony method was used; otherwise the BIONJ method with MCL distance matrix was used. The trees are drawn to scale, with branch lengths measured in the number of substitutions per site. All positions containing gaps and missing data were eliminated.

\section{Conclusions}

We have deployed high-throughput whole-genome sequencing to explore genetic diversity among isolates of $X \mathrm{~cm}$, the bacterial pathogen responsible for BXW, which is devastating banana and plantain crops in East Africa and threatens the food security of millions. To understand the evolution and geographical spread of this newly emerging pathogen, we need molecular markers such as SNPs. Given the high degree of genome sequence identity among isolates (99.9985\%), genome-wide sequencing is the only tractable way of discovering sequence polymorphisms and is beginning to be applied to bacterial phytopathogens [17].

The high degree of sequence similarity among isolates indicates a very recent origin of the pathogen. The molecular markers discovered here enabled us to reconstruct the phylogenetic relationships between $\mathrm{Xcm}$ isolates from diverse geographical locations within the known range of the pathogen in Africa. Interestingly, the isolates fell into two major sub-lineages. This may indicate that there have been at least two separate introductions of $\mathrm{Xcm}$ into the banana-growing regions around Lake Victoria. This contrasts with the widely held working assumption that $X \mathrm{~cm}$ spread from Ethiopia to Uganda and thence subsequently into neighboring countries. This view is largely based on the fact that $\mathrm{Xcm}$ was reported in Ethiopia in the late 1960s, then Uganda in 2001 and only later in other African countries (2004: D. R. Congo, 2005: Rwanda and Tanzania, 2006: Kenya and Burundi). However, it is possible that the disease has existed for some time before being officially reported, especially given the armed conflicts in D. R. Congo and Rwanda at the time. An alternative hypothesis is that all outbreaks in the region can be traced back to a single introduction of inoculum that contained some genetic diversity and that some genetic diversity is maintained within the population. Under that scenario, our results could be explained by stochastic effects of sampling error given such a small number of isolates. Therefore, there is a pressing need to collect and genotype many more isolates, including multiple isolates from within single outbreaks. On the other hand, where we have sequenced multiple isolates from a single geographical area (the five isolates from central Uganda and the three isolates from North Western Tanzania), only a single sub-lineage was observed. This would be an unlikely outcome if both sub-lineages were approximately equally abundant at these sites. Therefore, we currently favour the multiple-introduction model until further isolates and genetic data are available.

\section{Acknowledgments}

This study was supported by the National Agriculture Research Organisation, Uganda under the MSI/WorldBank grant 2009. The authors wish to thank Karen Moore and Alex Moorhouse for their invaluable technical assistance with sequencing and Marta De Torres Zabala for expert guidance to A.W. in the laboratory. 


\section{References}

1. Biruma, M.; Pillay, M.; Tripathi, L.; Blomme, G.; Abele, S.; Mwangi, M.; Bandyopadhyay, R.; Muchunguzi, P.; Kassim, S.; Nyine, M. Banana Xanthomonas wilt: A review of the disease, management strategies and future research directions. Afr. J. Biotechnol. 2007, 6, 953-962.

2. Yirgou, D.; Bradbury, J.F. Bacterial wilt of Enset (Ensete ventricosum) incited by Xanthomonas musacearum sp. n. Phytopathology 1968, 58, 111-112.

3. Yirgou, D.; Bradbury, J.F. A note on wilt of banana caused by the enset wilt organism Xanthomonas musacearum. East Afr. Agric. Forestry J. 1974, 40, 111-114.

4. Tushemereirwe, W.; Kangire, A.; Ssekiwoko, F.; Offord, L.C.; Crozier, J.; Boa, E.; Rutherford, M.; Smith, J.J. First report of Xanthomonas campestris pv. musacearum on banana in Uganda. Plant Pathol. 2004, 53, 802.

5. Ndungo, V.; Eden-Green, S.; Blomme, G.; Crozier, J.; Smith, J.J. Presence of banana Xanthomonas wilt (Xanthomonas campestris pv. musacearum) in the Democratic Republic of Congo (DRC). Plant Pathol. 2006, 55, 294.

6. Reeder, R.H.; Muhinyuza, J.B.; Opolot, O.; Aritua, V.; Crozier, J.; Smith, J. Presence of banana bacterial wilt (Xanthomonas campestris pv. musacearum) in Rwanda. Plant Pathol. 2007, 56, 1038.

7. Carter, B.A.; Reeder, R.; Mgenzi, S.R.; Kinyua, M.; Mbaka, J.N.; Doyle, K.; Nakato, V.; Mwangi, M.; Beed, F.; Aritua, V.; et al. Identification of Xanthomonas vasicola (formerly X. campestris pv. musacearum), causative organism of banana Xanthomonas wilt, in Tanzania, Kenya and Burundi. Plant Pathol. 2010, 59, 403.

8. Kubiriba, J.; Karamura, E.B.; Jogo, W.; Tushemereirwe, W.K.; Tinzaara, W. Community mobilization: A key to effective control of banana Xanthomonas wilt. J. Dev. Agric. Econ. 2012, 4, 125-131.

9. Namukwaya, B.; Tripathi, L.; Tripathi, J.N.; Arinaitwe, G.; Mukasa, S.B.; Tushemereirwe, W.K. Transgenic banana expressing Pflp gene confers enhanced resistance to Xanthomonas wilt disease. Transgenic. Res. 2011, doi:10.1007/s11248-011-9574-y.

10. Tripathi, L.; Mwaka, H.; Tripathi, J.N.; Tushemereirwe, W.K. Expression of sweet pepper Hrap gene in banana enhances resistance to Xanthomonas campestris pv. musacearum. Mol. Plant Pathol. 2010, 11, 721-731.

11. Aritua, V.; Parkinson, N.; Thwaites, R.; Heeney, J.V.; Jones, D.R.; Tushemereirwe, W.; Crozier, J.; Reeder, R.; Stead, D.E.; Smith, J. Characterization of the Xanthomonas sp. causing wilt of enset and banana and its proposed reclassification as a strain of X. vasicola. Plant Pathol. 2008, 57, 170-177.

12. Studholme, D.J.; Kemen, E.; MacLean, D.; Schornack, S.; Aritua, V.; Thwaites, R.; Grant, M.; Smith, J.; Jones, J.D. Genome-wide sequencing data reveals virulence factors implicated in banana Xanthomonas wilt. FEMS Microbiol. Lett. 2010, 310, 182-192.

13. Aritua, V.; Parkinson, N.; Thwaites, R.; Jones, D.R.; Tushemereirwe, W.; Smith, J.J. Molecular epidemiology of Xanthomonas campestris pv. musacearum, the causal agent of xanthomonas wilt of banana and enset. Acta Hort. (ISHS) 2009, 828, 219-226.

14. Ryan, R.P.; Vorhölter, F.J.; Potnis, N.; Jones, J.B.; van Sluys, M.A.; Bogdanove, A.J.; Dow, J.M. Pathogenomics of Xanthomonas: Understanding bacterium-plant interactions. Nat. Rev. Microbiol. 2011, 9, 344-355. 
15. Aritua, V.; Nanyonjo, A.; Kumakech, F.; Tushemereirwe, W. Rep-PCR reveals a high genetic homogeneity among Ugandan isolates of Xanthomonas campestris pv musacearum. Afr. J. Biotechnol. 2007, 6, 179-183.

16. Achtman, M. Insights from genomic comparisons of genetically monomorphic bacterial pathogens. Philos. Trans. R. Soc. Lond. B. Biol. Sci. 2012, 367, 860-867.

17. Cai, R.; Lewis, J.; Yanm, S.; Lium, H.; Clarkem, C.R.; Campanile, F.; Almeida, N.F.; Studholme, D.J.; Lindeberg, M.; Schneider, D.; Zaccardelli, M.; et al. The plant pathogen Pseudomonas syringae pv. tomato is genetically monomorphic and under strong selection to evade tomato immunity. PLoS Pathog. 2011, 7, e1002130.

18. Kodama, Y.; Shumway, M.; Leinonen, R. International nucleotide sequence database collaboration. The sequence read archive: Explosive growth of sequencing data. Nucleic Acids Res. 2012, 40, D54-D56.

19. Studholme, D.J.; Wasukira, A.; Paszkiewicz, K.; Aritua, V.; Thwaites, R.; Smith, J.; Grant, M. Draft Genome sequences of Xanthomonas sacchari and two banana-associated Xanthomonads reveal insights into the Xanthomonas Group 1 Clade. Genes 2011, 2, 1050-1065.

20. Zerbino, D.R.; Birney, E. Velvet: Algorithms for de novo short read assembly using de Bruijn graphs. Genome Res. 2008, 18, 821-829.

21. Benson, D.A.; Karsch-Mizrachi, I.; Clark, K.; Lipman, D.J.; Ostell, J.; Sayers, E.W. GenBank. Nucleic Acids Res. 2012, 40, D48-D53.

22. Lewis Ivey, M.L.; Tusiime, G.; Miller, S.A. A PCR assay for the detection of Xanthomonas campestris pv. musacearum in bananas. Plant Dis. 2010, 94, 109-114.

23. Adikini, S.; Tripathi, L.; Beeda, F.; Tusiime, G.; Magembe, E.M.; Kim, D.J. Development of a specific molecular tool for detecting Xanthomonas campestris pv. musacearum. Plant Pathol. 2011, 60, 443-452.

24. Adriko, J.; Aritua, V.; Mortensen, C.N.; Tushemereirwe, W.K.; Kubiriba, J.; Lund, O.S. Multiplex PCR for specific and robust detection of Xanthomonas campestris pv. musacearum in pure culture and infected plant material. Plant Pathol. 2012, 61, 489-497.

25. Li, H.; Durbin, R. Fast and accurate short read alignment with Burrows-Wheeler transform. Bioinformatics 2009, 25, 1754-1760.

26. Kuo, T.T.; Tan, M.S.; Su, M.T.; Yang, M.K. Complete nucleotide sequence of filamentous phage Cf1c from Xanthomonas campestris pv. citri. Nucleic Acids Res. 1991, 19, 2498.

27. Robinson, J.Y.; Thorvaldsdóttir, H.; Winckler, W.; Guttman, M.; Lander, E.S.; Getz, G.; Mesirov, J.P. Integrative Genomics Viewer. Nat. Biotechnol. 2011, 29, 24-26.

28. Tamura, K.; Nei, M. Estimation of the number of nucleotide substitutions in the control region of mitochondrial DNA in humans and chimpanzees. Mol. Biol. Evol. 1993, 10, 512-526.

29. Tamura, K.; Peterson, D.; Peterson, N.; Stecher, G.; Nei, M.; Kumar, S. MEGA5: Molecular evolutionary genetics analysis using maximum likelihood, evolutionary distance, and maximum parsimony methods. Mol. Biol. Evol. 2011, 28, 2731-2739.

(C) 2012 by the authors; licensee MDPI, Basel, Switzerland. This article is an open access article distributed under the terms and conditions of the Creative Commons Attribution license (http://creativecommons.org/licenses/by/3.0/). 